\title{
My burning issues in the neoadjuvant treatment for breast cancer
}

\author{
Elisabeth S. Bergen · Rupert Bartsch
}

Received: 28 November 2017 / Accepted: 5 December 2017 / Published online: 22 December 2017 (C) The Author(s) 2017. This article is an open access publication.

Summary A combination of anthracyclines and taxanes remains the standard of care for neoadjuvant chemotherapy (NACT) resulting in increased breast conservation rate (BCR) and decreased recurrence rate [1]. Whether pathological complete response (pCR) could be an appropriate surrogate parameter for long-term survival is still a matter of debate. In patients with triple-negative breast cancer (TNBC) and HER2-positive breast cancer (BC), a six to nine times higher risk for relapse has been reported if no pCR was achieved [2, 3]. Within these aggressive subtypes the strongest association between pCR and long-term outcome could be observed [4]. However, a pooled analysis of recently conducted trials could only identify pCR as a surrogate endpoint for improved event-free survival (EFS) and overall survival (OS) on an individual patient level as opposed to the trial level [5]. Even in TNBC, demonstrating that an increased pCR converts into a significant survival benefit would require a study population markedly larger than calculated for previously conducted trials $[6,7]$.

Keywords Neoadjuvant therapy · Breast cancer

\section{E. S. Bergen · R. Bartsch}

Comprehensive Cancer Center, Vienna, Austria

\section{E. S. Bergen · R. Bartsch $(\bowtie)$}

Department of Medicine 1, Clinical Division of

Oncology, Medical University of Vienna, Waehringer

Guertel 18-20, 1090 Vienna, Austria

rupert.bartsch@meduniwien.ac.at

R. Bartsch

German Breast Group, Neu-Isenburg, Germany

\section{Triple negative subtype}

About one third of patients with triple-negative breast cancer (TNBC) treated with standard NACT achieve pCR. Preclinical trials stated TNBC to be more sensitive to interstrand crosslinking agents such as platinum salts due to deficiencies in the BRCA-associated DNA repair mechanism [8]. Especially in BRCA1mutated patients treated with carboplatin as part of NACT, pCR rates of up to $75 \%$ could be reached [9]. So far, five randomized phase II and one phase III trial addressed the use of carboplatin as part of NACT for patients with TNBC (Table 1):

The GEICAM trial represents the only negative trial so far; here, a nonsignificant drop of pCR with the addition of carboplatin to docetaxel after an anthracycline-based regimen was reported ( $p=0.61)$ [10]. In the triple-negative population of GeparSixto, the addition of weekly carboplatin to weekly paclitaxel, nonpegylated liposomal doxorubicin and three-weekly bevacizumab increased pCR rates in breast/axilla from 43 to $57 \%(p=0.015)$ [11]. Of note, the control arm did not include cyclophosphamide. In the CALGB 40603 trial, $54 \%$ compared to $41 \%$ of patients had pCR with the addition of carboplatin when added to a standard chemotherapy backbone of paclitaxel followed by doxorubicin plus cyclophosphamide once every two weeks $(p=0.0029)$ [12]. The ADAPT triplenegative trial revealed a statistically significant benefit of carboplatin compared to gemcitabine when added to nab-paclitaxel $(p<0.001)$ [13]. Finally, the generic trial platform $i$-SPY 2 compared paclitaxel with or without an experimental combination of carboplatin and the PARP-inhibitor veliparib followed by doxorubicin and cyclophosphamide in 116 patients. Carboplatin and veliparib graduated with $88 \%$ predicted probability of success in a phase 3 study [14]. 
Table 1 Phase II and III trials investigating the addition of carboplatin to neoadjuvant chemotherapy regimens for triplenegative patients; in studies including other subtypes only the triple-negative population is quoted

\begin{tabular}{|c|c|c|c|c|c|}
\hline Study & Phase & Reference & $\begin{array}{l}\text { Chemotherapy back- } \\
\text { bone }\end{array}$ & Experimental therapy & $\mathrm{pCR}$ \\
\hline GEICAM/2006-03 & ॥ & Alba E et al. [10] & $\begin{array}{l}E C \times 4 \\
\text { followed by } D \times 4\end{array}$ & $\begin{array}{l}\operatorname{arm} 1: D \\
\operatorname{arm} 2: D+C b \text { AUC } 6\end{array}$ & $p=0.61$ \\
\hline GeparSixto & II & von Minckwitz et al. [11] & $\begin{array}{l}w P a c+N P L D+B e v \\
\text { for } 18 \text { weeks }\end{array}$ & $\begin{array}{l}\operatorname{arm} 1:+C b \text { AUC } 1.5 \\
\operatorname{arm~2:-Cb}\end{array}$ & $p=0.015$ \\
\hline CALGB 40603 & II & Sikov WM et al. [12] & $\begin{array}{l}\text { wPac } \times 12 \\
\text { followed by ddAC } \times 4\end{array}$ & $\begin{array}{l}\text { arm 1: wPac } \\
\text { arm 2: } w P a c+B e v \\
\text { arm 3: } w P a c+C b \text { AUC } 6 \times 4 \\
\text { arm 4: } w P a c+B e v+C p\end{array}$ & $p=0.0029$ \\
\hline WSG: ADAPT & ॥ & Gluz 0 et al. [13] & nab-Pac $\times 12$ & $\begin{array}{l}\text { arm 1: nab-Pac + Cb } \\
\text { arm 2: nab-Pac + Gem }\end{array}$ & $p<0.001$ \\
\hline$i-S P Y 2$ & $\begin{array}{l}\text { Generic trial plat- } \\
\text { form }\end{array}$ & Rugo H et al. [14] & $\begin{array}{l}\text { wPac } \times 12 \\
\text { followed by ddAC } \times 4\end{array}$ & $\begin{array}{l}\text { arm 1: wPac } \\
\text { arm 2: wPac + pla A } \\
\text { arm 3: wPac + pla B } \\
\text { arm 4: wPac + Cp AUC } 6+\text { Veli }\end{array}$ & $\begin{array}{l}88 \% \text { predicted } \\
\text { probability }\end{array}$ \\
\hline BRIGHTNESS & III & Geyer CE et al. [15] & $\begin{array}{l}\text { wPac } \times 12 \\
\text { followed by ddAC } \times 4\end{array}$ & $\begin{array}{l}\text { arm 1: } w P a c+\text { Cb AUC } 6+\text { Veli } \\
\text { arm 2: wPac + Cb + pla } \\
\text { arm 3: wPac + pla + pla }\end{array}$ & $\begin{array}{l}\text { arm } 1 \text { vs arm 3: } \\
p<0.001 \\
\text { arm } 1 \text { vs arm 2: } \\
p=0.36\end{array}$ \\
\hline
\end{tabular}

$E C$ epirubicin/cyclophosphamide; $D$ docetaxel; Cb carboplatin; wPac weekly paclitaxel; NPLD non-pegylated liposomal doxorubicin; Bev bevacizumab; $A U C$ area under the curve; $d d A C$ doxorubicin plus cyclophosphamide once every 2 weeks; nab-Pac nab-paclitaxel; Gem gemcitabine; pla placebo (A and B); Veli veliparib

BRIGHTNESS was the first randomized, placebocontrolled phase III trial investigating carboplatin for NACT; results were presented at the 2017 ASCO annual meeting. Triple-negative patients were randomized 1:1:2 to paclitaxel either alone or with carboplatin or with the combination of carboplatin and veliparib followed by doxorubicin plus cyclophosphamide. The addition of carboplatin and veliparib significantly increased pCR rates $(53.2 \%$ vs $31.0 \%, p<0.001)$, while addition of veliparib to carboplatin and paclitaxel did not demonstrate further improvement $(53.2 \%$ vs $57.5 \%, p=0.36$ ) [15].

In all of the trials, carboplatin was associated with significantly increased grade $3 / 4$ side effects with consecutive treatment discontinuations which clearly has to be weighed against improved activity. Summarizing current data, the benefit of carboplatin in the neoadjuvant setting could be clearly shown. Large prospective studies are needed to compare doses and schedules of carboplatin (AUC 1.5 or 2 weekly vs AUC 5 or 6 every 3 weeks) as well as chemotherapy backbones to reduce side effects and improve tolerability.

\section{HER2-positive subtype}

Achieving a pCR in HER2-positive patients results in a significantly better event-free and overall survival as shown in the Collaborative Trials in Neoadjuvant Breast Cancer (CTNeoBC) pooled analysis [5]. Dual targeting the HER2 receptor with trastuzumab and pertuzumab in combination with docetaxel results in a significantly higher proportion of patients achieving pCR compared to trastuzumab plus docetaxel alone $(p=0.014)$ [16]. Importantly, dual blockade does not increase the rate of symptomatic left ventricular systolic dysfunction as shown in the TRYPHAENA study [17]. Several trials also reported increased pCR rates with the vertical blockade of trastuzumab and lapatinib compared to trastuzumab in combination with paclitaxel. A limiting factor of all neoadjuvant trials investigating this combination clearly was the increase in toxicity and treatment discontinuations [18-20]. Within all HER2-positive trials, a lower pCR rate was obtained in estrogen receptor(ER)-positive patients highlighting the distinct tumor biology of this subtype and the need for predictive biomarkers.

Of note, in the $N O A H$ study, the pCR increase from 19 to $38 \%$ by adding trastuzumab to NACT was reflected in improved event-free survival (EFS) since it was the only neoadjuvant trial powered for this endpoint [21].

\section{Luminal subtype}

Currently, NACT in luminal patients remains on option preferentially for large and/or highly proliferative tumors as it may be less effective in estrogen receptor (ER)-positive compared to ER-negative tumors [22].

So far, two randomized phase II trials compared the efficacy and tolerability of preoperative endocrine therapy (ET) and chemotherapy in luminal populations. Semiglazov et al. randomized 239 patients with IIa to IIIb luminal tumors to four cycles of anthracyclines and taxanes for 12 weeks or ET with anastrozole or exemestane for 3 months. Beside the limitation of missing HER2 status and the suboptimal chemotherapy backbone, no differences in clinical or pathological response could be determined between treatment groups [23]. In another randomized phase II trial including premenopausal patients, higher clinical response rates could be observed with an anthracycline-cyclophosphamide combination followed by 
taxanes compared to exemestane (in combination with goserelin if patients were premenopausal) (66\% vs $48 \% ; p=0.075)$. In contrast, in the subpopulation of patients with a low proliferation rate, response rates had been similar in both arms $(63 \%$ vs $58 \%$; $p=$ 0.74) [24].

Therefore, neoadjuvant ET may be a feasible and well-tolerated option for postmenopausal women with either low proliferating tumors, comorbid conditions and/or advanced age.

\section{Conclusions}

Neoadjuvant instead of adjuvant therapy is the preferred treatment approach for clinical stage II and III TNBC and HER2-positive BC as stated by the St. Gallen Consensus Conference [25]. pCR as primary endpoint allows objective evaluation of treatment sensitivity. On an individual patient level, pCR correlates with improved long-term outcome.

Funding Open access funding provided by Medical University of Vienna.

Conflict of interest E.S. Bergen and R. Bartsch declare that they have no competing interests.

Open Access This article is distributed under the terms of the Creative Commons Attribution 4.0 International License (http://creativecommons.org/licenses/by/4.0/), which permits unrestricted use, distribution, and reproduction in any medium, provided you give appropriate credit to the original author(s) and the source, provide a link to the Creative Commons license, and indicate if changes were made.

\section{References}

1. Kaufmann M, Hortobagyi GN, Goldhirsch A, Scholl S, Makris A, Valagussa P, et al. Recommendations from an international expert panel on the use of neoadjuvant (primary) systemic treatment of operable breast cancer: an update. JClin Oncol. 2006;24(12):1940-9.

2. Liedtke C, Mazouni C, Hess KR, Andre F, Tordai A, Mejia JA, et al. Response to neoadjuvant therapy and long-term survival in patients with triple-negative breast cancer. JClin Oncol. 2008;26(8):1275-81.

3. Untch M, Fasching PA, Konecny GE, Hasmuller S, Lebeau A, Kreienberg R, et al. Pathologic complete response after neoadjuvant chemotherapy plus trastuzumab predicts favorablesurvival inhuman epidermal growthfactor receptor 2-overexpressing breast cancer: results from the TECHNO trial of the AGO and GBG study groups. J Clin Oncol. 2011;29(25):3351-7.

4. von Minckwitz G, Untch M, Blohmer JU, Costa SD, Eidtmann H, Fasching PA, et al. Definition and impact of pathologic complete response on prognosis after neoadjuvant chemotherapy in various intrinsic breast cancer subtypes. JClin Oncol. 2012;30(15):1796-804.

5. Cortazar P, Zhang L, Untch M, Mehta K, Costantino JP, WolmarkN, etal. Pathological complete response andlongterm clinical benefit in breast cancer: the CTNeoBC pooled analysis. Lancet. 2014;384(9938):164-72.

6. Berry DA, Hudis CA. Neoadjuvant therapy in breast cancer as a basis for drug approval. JAMA Oncol. 2015;1(7):875-6.
7. Hatzis C, Symmans WF, Zhang Y, Gould RE, Moulder SL, Hunt KK, et al. Relationship between complete pathologic response to neoadjuvant chemotherapy and survival in triple-negative breast cancer. Clin Cancer Res. 2016;22(1):26-33.

8. Hurley J, Reis IM, Rodgers SE, Gomez-Fernandez C, Wright J, Leone JP, et al. The use of neoadjuvant platinumbased chemotherapy in locally advanced breast cancer that is triple negative: retrospective analysis of 144 patients. Breast Cancer Res Treat. 2013;138(3):783-94.

9. Silver DP, Richardson AL, Eklund AC, Wang ZC, Szallasi Z, Li $\mathrm{Q}$, et al. Efficacy of neoadjuvant cisplatin in triple-negative breast cancer. JClin Oncol. 2010;28(7):1145-53.

10. Alba E, Chacon JI, Lluch A, Anton A, Estevez L, Cirauqui B, et al. A randomized phase II trial of platinum salts in basal-like breast cancer patients in the neoadjuvant setting. Results from the GEICAM/2006-03, multicenter study. Breast Cancer Res Treat. 2012;136(2):487-93.

11. von Minckwitz G, Schneeweiss A, Loibl S, Salat C, Denkert C, Rezai M, et al. Neoadjuvant carboplatin in patients with triple-negative and HER2-positive early breast cancer (GeparSixto; GBG 66): a randomised phase 2 trial. Lancet Oncol. 2014;15(7):747-56.

12. Sikov WM, Berry DA, Perou CM, Singh B, Cirrincione CT, Tolaney SM, et al. Impact of the addition of carboplatin and/or bevacizumab to neoadjuvant once-per-week paclitaxel followed by dose-dense doxorubicin and cyclophosphamide on pathologic complete response rates in stage II to III triple-negative breast cancer: CALGB 40603 (Alliance). JClin Oncol. 2015;33(1):13-21.

13. Gluz O, Nitz U, Liedtke C, et al. Abstract S6-07: Comparison of 12 weeks neoadjuvant Nab-paclitaxel combined with carboplatinum vs. gemcitabine in triple- negative breast cancer: WSG-ADAPT TN randomized phase II trial. presented at SABCS. 2015. pp. 6-7.

14. Rugo HS, Olopade OI, DeMichele A, Yau C, van 't Veer LJ, Buxton MB, et al. Adaptive randomization of VeliparibCarboplatin treatment in breast cancer. N Engl J Med. 2016;375(1):23-34.

15. Geyer CE et al. Abst. \#520; presented at the 2017 ASCO Annual Meeting, June 2017, Chicago, USA

16. Gianni L, Pienkowski T, Im YH, Roman L, Tseng LM, Liu $\mathrm{MC}$, et al. Efficacy and safety of neoadjuvant pertuzumab and trastuzumab in women with locally advanced, inflammatory, or early HER2-positive breast cancer (NeoSphere): a randomised multicentre, open-label, phase 2 trial. Lancet Oncol. 2012;13(1):25-32.

17. Schneeweiss A, Chia S, Hickish T, Harvey V, Eniu A, Hegg $\mathrm{R}$, et al. Pertuzumab plus trastuzumab in combination with standard neoadjuvant anthracycline-containing and anthracycline-free chemotherapy regimens in patients with HER2-positive early breast cancer: a randomized phase II cardiac safety study (TRYPHAENA). Ann Oncol. 2013;24(9):2278-84.

18. Baselga J, Bradbury I, Eidtmann H, Di Cosimo S, de Azambuja E, Aura C, et al. Lapatinib with trastuzumab for HER2-positive early breast cancer (NeoALTTO): a randomised, open-label, multicentre, phase 3 trial. Lancet. 2012;379(9816):633-40.

19. Robidoux A, Tang G, Rastogi P, Geyer CE Jr., Azar CA, Atkins JN, et al. Lapatinib as a component of neoadjuvant therapy for HER2-positive operable breast cancer (NSABP protocol B-41): an open-label, randomised phase 3 trial. Lancet Oncol. 2013;14(12):1183-92.

20. Carey LA, Berry DA, Cirrincione CT, Barry WT, Pitcher BN, Harris LN, et al. Molecular heterogeneity and response to Neoadjuvant human epidermal growth factor receptor 
2 targeting in CALGB 40601, a randomized phase III trial of Paclitaxel plus Trastuzumab with or without Lapatinib. JClin Oncol. 2016;34(6):542-9.

21. Gianni L, Eiermann W, Semiglazov V, Manikhas A, Lluch A, Tjulandin S, et al. Neoadjuvant chemotherapy with trastuzumab followed by adjuvant trastuzumab versus neoadjuvant chemotherapy alone, in patients with HER2positive locally advanced breast cancer (the NOAH trial): a randomised controlled superiority trial with a parallel HER2-negative cohort. Lancet. 2010;375(9712):377-84.

22. Colleoni M, Gelber S, Coates AS, Castiglione-Gertsch M, Gelber RD, Price K, et al. Influence of endocrine-related factors on response to perioperative chemotherapy for patients with node-negative breast cancer. J Clin Oncol. 2001;19(21):4141-9.

23. Semiglazov VF, Semiglazov VV, Dashyan GA, Ziltsova EK, Ivanov VG, Bozhok AA, et al. Phase 2 randomized trial of primary endocrine therapy versus chemotherapy in postmenopausal patients with estrogen receptor-positive breast cancer. Cancer. 2007;110(2):244-54.
24. Alba E, Calvo L, Albanell J, Arcusa Lanza A, Chacon JI, et al. Chemotherapy (CT) and hormonotherapy (HT) as neoadjuvant treatment in luminal breast cancer patients: results from the GEICAM/2006-03, a multicenter, randomized, phase-II study. Ann Oncol. 2012;23(12):3069-74.

25. Curigliano G, Burstein HJ, Winer EP, Gnant M, Dubsky P, Loibl S, et al. De-escalating and escalating treatments for early-stage breast cancer: the St. Gallen International Expert Consensus Conference on the Primary Therapy of Early Breast Cancer 2017. Ann Oncol. 2017;28(8):1700-12.

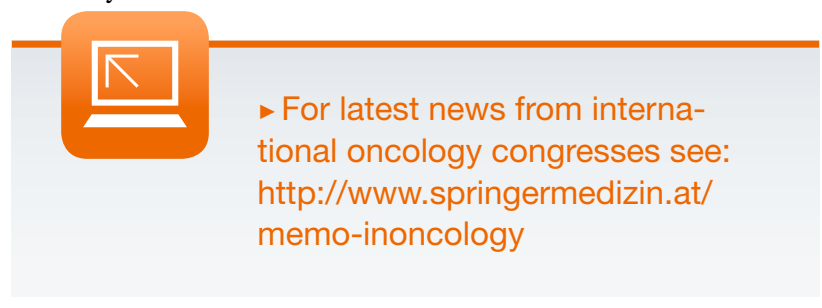

